\title{
What is the object of the encapsulation of a process?
}

Gary Davis

University of Southampton

United Kingdom
David Tall

University of Warwick

United Kingdom
Michael Thomas

University of Auckland

New Zealand

Several theories have been proposed to describe the transition from process to object in mathematical thinking. Yet, what is the nature of this "object" produced by the "encapsulation" of a process? Here we outline the development of some of the theories (including Piaget, Dienes, Davis, Greeno, Dubinsky, Sfard, Gray \& Tall) and consider the nature of the mental objects (apparently) produced through encapsulation, and their role in the wider development of mathematical thinking. Does the same developmental route occur in geometry as in arithmetic and algebra? Is the same development used in axiomatic mathematics? What is the role played by visualisation?

\section{Theories of encapsulation/reification}

In recent years there has been great interest in the encapsulation (or reification) of a process into a mental object as a fundamental method of cognitive development in mathematical thinking. Piaget focused on the idea of a process becoming a mental object, noting how "actions and operations become thematized objects of thought or assimilation". Dienes (1960), following Piaget, used a grammatical metaphor to formulate how a predicate (or action) becomes the subject of a further predicate, which may in turn become the subject of another. Davis formulated the same basic idea a quarter of a century later:

When a procedure is first being learned, one experiences it almost one step at time; the overall patterns and continuity and flow of the entire activity are not perceived. But as the procedure is practised, the procedure itself becomes an entity - it becomes a thing. It, itself, is an input or object of scrutiny. All of the full range of perception, analysis, pattern recognition and other information processing capabilities that can be used on any input data can be brought to bear on this particular procedure. Its similarities to some other procedure can be noted, and also its key points of difference. The procedure, formerly only a thing to be done - a verb - has now become an object of scrutiny and analysis; it is now, in this sense, a noun.

(Davis, 1984, pp. 29-30.)

He went on to distinguish a visually moderated sequence where each step is written down and prompts the next until the problem is solved and an integrated sequence, conceived as a whole which may itself be organised into sub-procedures. He also used the term "procedure" as a specific algorithm for implementing a "process" in an information-processing sense (Davis, 1983, p. 257).

At this time information-processing was focusing on the way in which a procedure which could be used as an input to another procedure could be conceived as a "conceptual entity" (Greeno, 1983).

The notion of the transformation of a process into an object took new impetus in the work of Dubinsky (1991) and Sfard (1991). Sfard hypothesised two approaches to concept development, one operational focusing on processes, the other structural, focusing on objects. 
A constant three-step pattern can be identified in the successive transitions from operational to structural conceptions: first there must be a process performed on the already familiar objects, then the idea of turning this process into a more compact, selfcontained whole should emerge, and finally an ability to view this new entity as a permanent object in its own right must be acquired. These three components of concept development will be called interiorization, condensation, and reification, respectively.

Condensation means a rather technical change of approach, which expresses itself in an ability to deal with a given process in terms of input/output without necessarily considering its component steps.

Reification is the next step: in the mind of the learner, it converts the already condensed process into an object-like entity. ... The fact that a process has been interiorized and condensed into a compact, self-sustained entity, does not mean, by itself, that a person has acquired the ability to think about it in a structural way. Without reification, her or his approach will remain purely operational.

(Sfard, 1992, pp. 64-65)

Dubinsky (1991) and his colleagues (Cottrill et al, in press) formulate the encapsulation of process into object as three stages of a four part theory with the acronym APOS. An action becomes repeatable as a recognised process, is then encapsulated as a mental object to later become part of a mental schema.

The notion of action and process are characterised in a manner reminiscent of the notions of visually moderated sequence and integrated sequence of Davis:

An action is any physical or mental transformation of objects to obtain other objects. It occurs as a reaction to stimuli which the individual perceives as external. It may be a single step response, such as a physical reflex, or an act of recalling some fact from memory. It may also be a multi-step response, by then it has the characteristic that at each step, the next step is triggered by what has come before, rather than by the individual's conscious control of the transformation. ... When the individual reflects upon an action, he or she may begin to establish conscious control over it. We would then say that the action is interiorized, and it becomes a process. (Cottrill, et al, in press, (our italics))

The action becomes a process when the individual can "describe or reflect upon all of the steps in the transformation without necessarily performing them." A process becomes an object when "the individual becomes aware of the totality of the process, realizes that transformations can act on it, and is able to construct such transformations."

The final part of the APOS structure occurs when "actions, process and objects ... are organised into structures, which we refer to as schemas." Here the suggestion is made that

"an individual can reflect on a schema and act upon it. This results in the schema becoming a new object. Thus we now see that there are at least two ways of constructing objects - from processes and from schemas."

(Cottrill, et al, in press, (our italics)) 
By considering the developments of concepts in simple arithmetic of whole numbers, Gray \& Tall (1994) reviewed how a lengthy procedure such as "count-all" (count one set, count another, put the sets together and count all) became compressed into a shorter procedure "count-on" (with various variations such as "count-both", "count-on-fromlarger), whilst also developing other techniques, such as remembering "known facts" and "deriving facts" from a combination of number facts and counting. This shows a number of different procedures being used to carry out essentially the same process in increasingly sophisticated ways. The symbol $4+2$ occupies a pivotal role, as the process of addition (by a variety of procedures) and as the concept of sum. Soon the cognitive structure grows to encompass the fact that $4+2,2+4,3+3,2$ times 3 , are all essentially the same mental object. They therefore defined:

An elementary procept is the amalgam of three components: a process which produces a mathematical object, and a symbol which is used to represent either process or object.

A procept consists of a collection of elementary procepts which have the same object.

(Gray \& Tall, 1994)

This notion of procept proved to be present throughout a large portion of mathematics. Tall \& Thomas (1991) had already noted that, for many children, an expression such as $2+3 x$ may be conceived as a process which cannot be carried out until the value of $x$ is not known - a reinterpretation of the notion of "lack of closure" discussed by earlier authors. Gray and Tall (1994) also noted the peculiar case of the limit concept where the (potentially infinite) process of computing a limit may not have a finite algorithm at all. Thus a procept may exist which has both a process (tending to a limit) and a concept (of limit), yet there is no procedure to compute the desired result.

Table 1 shows a summary of the discussion so far. It does not intend any direct correspondence between the stages of the theories, simply that each passes through a development of growing sophistication from some kind of process/procedure usually performed step-by-step and ending with an object/concept that can be manipulated as an entity in its own right. The intermediate stages specified in each line are not intended to correspond directly, for instance, Greeno's "input to another procedure" is essentially the same as conceiving a programming procedure as an entity, whereas Dubinsky's characterises the individual's ability to take control of a repeatable action, and Sfard's focus is on the ability to think of the process as a input/output without needing to consider the intermediate steps.

\begin{tabular}{|c|c|c|c|}
\hline Piaget (50s) & $\operatorname{action}(\mathrm{s}) \ldots$ & $\ldots$ & thematised object \\
\hline Dienes (60s) & predicate ... & $\ldots$ & subject \\
\hline Davis (80s) & $\begin{array}{l}\text { visually moderated } \\
\text { sequence ... } \\
\text { each step prompts the } \\
\text { next }\end{array}$ & $\begin{array}{l}\text { integrated sequence .... } \\
\text { seen as a whole, can } \\
\text { be broken into sub- } \\
\text { sequences }\end{array}$ & $\begin{array}{l}\text { a thing, an entity, } \\
\text { a noun }\end{array}$ \\
\hline Greeno (80s) & procedure ... & $\begin{array}{l}\text { input to another } \\
\text { procedure ... }\end{array}$ & conceptual entity \\
\hline Dubinsky (80s) & $\begin{array}{l}\text { action ... } \\
\text { each step triggers the } \\
\text { next }\end{array}$ & $\begin{array}{l}\text { interiorized process ... } \\
\text { with conscious control }\end{array}$ & $\begin{array}{l}\text { encapsulated } \\
\text { object }\end{array}$ \\
\hline Sfard (80s) & $\begin{array}{l}\text { interiorized process ... } \\
\text { process performed }\end{array}$ & $\begin{array}{l}\text { condensed process ... } \\
\text { process self-contained }\end{array}$ & reified object \\
\hline $\begin{array}{l}\text { Gray \& Tall } \\
\text { (90s) }\end{array}$ & $\begin{array}{l}\text { procedure ... } \\
\text { specific algorithm }\end{array}$ & $\begin{array}{l}\text { process ... } \\
\text { conceived as a whole, } \\
\text { irrespective of } \\
\text { algorithm }\end{array}$ & $\begin{array}{l}\text { procept } \\
\text { symbol evoking } \\
\text { process or concept }\end{array}$ \\
\hline
\end{tabular}


Table 1 : The transition between process and object

The wider literature of the various authors suggests further similarities and differences between their ideas. For instance, there seems to be broad agreement that a function as a process is determined as a whole by input-output, regardless of the internal procedure of computation. Thus the functions $f(x)=2 x+2$ and $g(x)=2(x+2)$ are one and the same as processes-even though the arithmetic procedures to compute them have a different sequence of operations. The intermediate stage(s) intimate how (one or more) specific procedures become seen as a single process without needing to carry out the intermediate steps.

What seems more problematic is to explain precisely what is meant by the "object" hypothesised to be constructed by reification/encapsulation.

\section{What is the "object" of encapsulation?}

Dörfler questioned the nature of the object formed by encapsulation:

... my subjective introspection never permitted me to find or trace something like a mental object for, say, the number 5 . What invariably comes to my mind are certain patterns of dots or other units, a pentagon, the symbol 5 or $\mathrm{V}$, relations like $5+5=10$, $5 * 5=25$, sentences like five is prime, five is odd, 5/30, etc., etc. But nowhere in my thinking I ever could find something objectlike that behaved like the number 5 as a mathematical object does. But nevertheless I deem myself able to talk about the number "five" without having distinctly available for my thinking a mental object which I could designate as the mental object " 5 ".

(Dörfler, 1993, pp. 146-147.)

Support for this view comes from interviews on a video produced by Gray \& Tall (1993) in which individuals were asked the following two questions:

What does the word "triangle" mean to you?

What does the word "five" mean to you?

The first was invariably met with a description or definition of a three sided figure as if the individual had a clear mental picture of what was being described, sometimes adding other properties, such as "the angles add up to 180". The second invariably caused the difficulties described by Dörfler, with some individuals describing "five objects", or a property such as "it's one bigger than four", yet not being able to describe what the term "five" meant of itself. However, all were secure when asked to operate with the number "five", for instance, that "five plus five" evoked the response "ten".

We hypothesise that the distinction between the notion "triangle" (which most would consider as an "object") and "five", which Dörfler suggests is not, is the difference between what we would term a "perceived object" and a "conceived object". The first occurs based on perceptual information - seeing a triangle, physically cutting out a triangle, touching it, feeling the corners, counting the edges. The focus is therefore on specific physical manifestations of the notion of a triangle. The second occurs when there is reflection on perceptions and actions, so the focus is no longer on the specific physical manifestations but on the actions/processes performed upon them .

Piaget, as usual, has made pertinent comments in this direction, long before any of the rest of us. He distinguishes between empirical abstraction deriving knowledge from the properties inherent in real-world objects and pseudo-empirical abstraction deriving knowledge from the processes which the individual performs on the objects. 
A procept, such as number, is a conceived object formed by pseudo-empirical abstraction. It focuses on the process of counting, building to the idea that different ways of counting the same set give the same result, leading to the concept of number. Even though there may be no mental object corresponding precisely to the number " 5 " as there is with a perceived object, there is a huge cognitive structure built up allowing the individual to use the symbol 5 as if it refers to an object. The number " 5 " has a concept image, in the sense of Tall \& Vinner (1981), consisting of "all the mental pictures and associated properties and processes" related to the concept in the mind of the individual.

There is in practice an intimate connection between conceived objects and operationally defined concepts:

With regard to icons, Piaget's distinction between the "figurative" and the "operative" would seem to be of some importance. Number is not a perceptual but a conceptual construct; thus it is operative and not figurative. Yet, perceptual arrangements can be used to "represent" a number figuratively. Three scratches on a prehistoric figurine, for instance, can be interpreted as a record of three events. In that sense they may be said to be "iconic" but their iconicity is indirect.

(Von Glaserfeld, 1987, p. 233).

We suggest that the total cognitive structure of the concept image of number, with its power to manipulate the symbols and to think of their properties, gives number an object status. What matters more is not what it is, but what we can do with it.

The "non-existence" of an "object" corresponding to a number is not as strange as at first seems. Consider, for example, the notion of "animal", which includes cats, dogs and gorillas. When we mentally picture an "animal", which one do we "see"? The name "animal" is a signifier which can be used to signify any of a wide number of particular instances but we appear to fail to have a single mental object which is "an animal." Nevertheless, to paraphrase Dörfler, although we may fail to have a unique mental object for "an animal" we deem ourselves able to talk about it.

\section{The scope of the process-object construction}

Once the possibility is conceded that the process-product construction can be conceived as an "object", the flood-gates open. By "acting upon" such an object, the actionprocess-object construction can be used again and again.

.. the whole of mathematics may therefore be thought of in terms of the construction of structures, ... mathematical entities move from one level to another; an operation on such 'entities' becomes in its turn an object of the theory, and this process is repeated until we reach structures that are alternately structuring or being structured by 'stronger' structures. (Piaget, 1972, p. 70)

The various proponents of process-object construction claim a different scope for the application of their theories. For Dubinsky, following Piaget, a process is any cognitive process. The notion of "permanent object" arises through "encapsulating the process of performing transformations in space which do not destroy the physical object" (Dubinsky et al, 1988, p. 45). A "perceived object" in our sense is, for Dubinsky, formed by process-object encapsulation. He also sees the theory of encapsulation applying equally well to the logical construction of formal concepts in advanced mathematics. He also acknowledged that there may be many cognitive processes involved in the construction of a mental object, used in an increasingly coherent 
manner, leading naturally to his later assertion that objects can also be formed by encapsulating schemas. Dubinsky therefore offers a single, unified theory of encapsulating cognitive processes as cognitive objects.

However, Piaget's distinction between empirical abstraction and pseudoempirical abstraction suggests a further subdivision of the growth of knowledge into constructions focusing on objects being acted upon, and those focusing on actions (and their subsequent symbolisation and conception as encapsulated objects).

Sfard's theory of the complementarity of operational and structural sees "two sides of the same coin", one focusing on operations and the other on the structure of objects and relationship between them. This is applied throughout mathematics. For instance, she classifies solutions to the find the number of boys when "the boys outnumber the girls by four" as operational in a form such as "add four to the number of girls" and structural as " $x=y+4 "$ (Sfard, 1995, p. 21). In an apparently similar style, Kieran (1992) considers the (arithmetical) evaluation of an expression such as $2 x+3$ for a numerical value of $x$ as "operational" but their manipulation as "structural". But there is a subtle distinction in meaning, for what is "structural" for Kieran becomes "operational" at a higher level in the sense of Piaget and Sfard, once the expressions are thought of as manipulable objects.

Further information on the distinction between the two types of conception include the idea that a structural conception is "supported by visual imagery" whilst an operational conception is "supported by verbal representations" (Sfard, 1991, p. 33). Thus the graph of a function is considered structural, whilst the algebraic expression for a function may be structural or operational. A set-theoretic definition of a function as a "set of ordered pairs" (with its graphical interpretation) is also considered as "structural" (ibid., pp. 5, 6). When proof by induction is considered, Sfard (1989, p. 151) classifies them as follows:

- Operational: for a property $\mathrm{P}(n)$, prove $\mathrm{P}(1)$ and that $\mathrm{P}(k) \Rightarrow \mathrm{P}(k+1)$ for all $k$ to establish the truth of $\mathrm{P}(n)$ for all natural numbers $n$,

- Structural: given a set $S \subseteq N$, prove $1 \in S$ and $k \in S \Rightarrow k+1 \in S$, to establish $S=N$.

To highlight the structural way in which the visual can be used to suggest theorems,. Sfard (1994) provides empirical evidence in which mathematicians use visual and spatial metaphors to provide them with "intimate familiarity" with structure that gives "direct insight into the properties of mathematical objects."

Skemp (1979), separates out the act of building a concept from its more formal testing. For instance, Archimedes used his "Method" to imagine lines making up a surface to "build" formulae for area, and then "tested" them using "proof by exhaustion" for formal publication. In the same way many mathematicians use intuitive structural conceptions as private constructs before releasing formally presented theories for public scrutiny. This once again suggests that the "structural" properties of objects could be usefully further subdivided, on the one hand through the teasing out of properties of objects, and on the other, specifying some of these properties as criteria to use for the basis of formal deduction of properties.

Gray \& Tall's notion of procept only occupies part of this scenario because their notion of "process" is a mathematical process represented by the mathematical symbolism. Neither the child's notion of "permanent object", nor the concept of "triangle" are procepts because neither has a symbol evoking either process or concept.

A theory of the cognitive development of mathematical concepts from childhood to professional mathematician is outlined in Tall, (1995). It begins by noting (as did Sfard) that, when an individual performs actions on objects, the focus of attention may be either on the objects, or on the actions (and their symbolisation), or on a combination of both. A focus on the processes in arithmetic leads to their encapsulation as arithmetic procepts (Gray \& Tall, 1994). Elsewhere procepts have different characteristics which may be described using different adjectives, for instance, computational procepts in 
arithmetic having built-in processes of computation, template procepts in algebra, with internal numerical evaluation for specific values of variables and external manipulation of algebraic expressions, or the limit procepts of the calculus.

A focus on objects, as in geometry, leads to a different sequence of events-teasing out the properties of the objects, making verbal descriptions, thinking about relationships, verbalising inferences, formulating verbal proofs, leading to a broad development after the fashion described by Van Hiele (1986).

Focusing on both operational processes and the properties of objects-either in turn or at the same time-gives a versatile approach (Tall \& Thomas, 1991). This proves particular valuable when computer software is available to carry out the processes internally, allowing the individual to focus either on the study of the processes, which they may carry out, or program, for themselves, or on the concepts produced by the computer (Tall \& Thomas, 1989). Versatile approaches have proved successful using visual properties, such as viewing the "local straightness" of graphs to complement the process of symbolic differentiation to give a derivative function (Tall, 1985), and also using process/concept, such as studying the evaluation of expressions (carried out by the student) separately from the properties of (equivalent) expressions, evaluated by the computer (Thomas, 1988).

One final case of "process-object" construction, in the sense of Dubinsky, is the notion of a defined object. In the sense of Sfard, this has structural overtones because the definition specifies certain structural criteria. However, constructing objects from definitions is cognitively subtle. There may be well-known examples of the defined object which all seem to have a common property, and yet this property may not follow from the specified criteria. For instance, the notion of triangle carries with it the properties inherent in 2 dimensional space. Its angles add up to $180^{\circ}$. Yet if a triangle is defined formally in some other type of geometry, for instance the geometry on the surface of a sphere, then the sum of its angles may be different. Just try cutting the skin of an orange and see. Two cuts through the "north pole" at right angles to one another meeting a cut round the equator will give a spherical triangle with three right angles, adding up to $270^{\circ}$.

We ask, just as we have before, "what is the object obtained by the processes of definition and deduction?" For instance, if we write down the axioms for a mathematical group, in what sense is there an object which we call "a group"? We arrive at the same conundrum as before. We speak of "an animal" without necessarily having in our mind's eye a visual mental image for a "general animal", we know how to manipulate "5" without having a specific mental image for it as an object. Likewise we can build up the properties of a "defined object" by deduction from the given criteria (axioms). For instance, we might deduce that "there is only one, unique, identity element in a group". Theorems deduced in this way are then properties shared by all structures which satisfy the criteria. We just use the same linguistic conventions in speaking of "a group" as we do in speaking of "an animal". For instance, we can say "a group has a unique identity element."

We have discussed three kinds of object construction: perceived objects, which are general concepts arising from teasing out the properties of specific objects, procepts, which involve symbolising processes so that the symbols can be manipulated as objects, and defined objects, arising from specifying criteria from which properties may be deduced by formal proof. The "object" of the encapsulation of a process is a way of thinking which uses a rich concept image to allow it to be a manipulable entity, in part by using mental processes and relationships to do mathematics and in part to use a name or symbol to mentally manipulate to think about mathematics. 


\section{References}

Cottrill, J., Dubinsky, E., Nichols, D., Schwingendorf, K., Thomas, K. \& Vidakovic, D. (in press). 'Understanding the limit concept: beginning with a coordinated process schema', Journal of Mathematical Behavior.

Davis, R. B. (1983). Complex Mathematical Cognition. In H. P. Ginsburg (Ed.) The Development of Mathematical Thinking, Academic Press, New York, 254-290.

Davis, R. B. (1984). Learning mathematics: the cognitive science approach to mathematics education. Norwood, NJ: Ablex.

Dienes, Z. P. (1960). Building up Mathematics, Hutchinson Educational: London.

Dörfler, W. (1993). Fluency in a discourse or manipulation of mental objects, Proceedings of PME 17, Tsukuba, Japan, II, 145-152.

Dubinsky, E. (1991). Reflective Abstraction in Advanced Mathematical Thinking. In D. Tall (Ed.) Advanced Mathematical Thinking, Kluwer: Dordrecht, 95-123.

Dubinsky, Elterman \& Gong. (1988). The Student's Construction of Quantification. For the Learning of Mathematics 8, 2. 44-51.

Gray \& Tall (1993) Can You Count On It? Video available from Mathematics Education Research Centre, Warwick University, UK.

Gray, E. M., \& Tall D. O. (1991). Duality, Ambiguity and Flexibility in Successful Mathematical Thinking, Proceedings of PME XIII, Assisi, Vol. II 72-79.

Gray, E. M. \& Tall, D. O. (1994). Duality, Ambiguity and Flexibility: A Proceptual View of Simple Arithmetic, The Journal for Research in Mathematics Education, $262,115-141$.

Greeno, J. (1983). Conceptual Entities. In D. Genter \& A. L. Stevens (Eds.), Mental Models, 227-252.

Kieran, (1992). The Learning and Teaching of School Algebra. In D. A. Grouws (Ed.) The Handbook of Research on Mathematics Teaching and Learning, (pp. 390-419), New York: Macmillan.

Piaget, J. (1972). The Principles of Genetic Epistemology (W. Mays trans.) London: Routledge \& Kegan Paul.

Sfard, A. (1989). Transition from Operational to Structural Conception: The notion of function revisited, Proceedings of PME XIII, Paris, 151-158.

Sfard, A. (1991). On the Dual Nature of Mathematical Conceptions: Reflections on processes and objects as different sides of the same coin, Educational Studies in Mathematics, 22, 1-36.

Sfard, A. (1992). Operational origins of mathematical objects and the quandary of reification - the case of function. In G. Harel \& E. Dubinsky (eds.), The Concept of Function: Aspects of Epistemology and Pedagogy, MAA Notes 25, (pp. 59-84). Washington DC: MAA.

Sfard, A. (1994). Reification as the Birth of Metaphor. For the Learning of Mathematics, 14, 1, 44-55.

Sfard, A. (1995). The Development of Algebra: Confronting Historical and psychological Perspectives, Journal of Mathematical Behavior, 14, 15-39.

Skemp, R. R. (1979). Intelligence, Learning and Action, London: Wiley.

Tall, D. O. (1985). Understanding the calculus, Mathematics Teaching 110 49-53.

Tall, D. O. \& Thomas, M. O. J. (1989). Versatile Learning and the Computer, Focus, 11 $2,117-125$.

Tall, D. O. \& Thomas, M. O. J. (1991). Encouraging Versatile Thinking in Algebra using the Computer, Educational Studies in Mathematics, 22 2, 125-147.

Tall, D. O. \& Vinner, S. (1981). Concept image and concept definition in mathematics, with special reference to limits and continuity, Educational Studies in Mathematics, 12, 151-169.

Tall, D. O. (1995). Mathematical Growth in Elementary and Advanced Mathematical Thinking, plenary address. In L. Meira \& D. Carraher, (Eds.), Proceedings of PME 19, Recife, Brazil, I, 61-75. 
Thomas, M. O. J. (1988). A Conceptual Approach to the Early Learning of Algebra Using a Computer, Ph.D. Thesis, The University of Warwick, UK.

Van Hiele, P. (1986). Structure and Insight. Orlando: Academic Press.

Von Glaserfeld, E. (1987). Preliminaries in any Theory of Representation. In Janvier, (Ed) Problems of Representation in the Teaching and Learning of Mathematics. NJ: Lawrence Erlbaum Associates, 214-225. 